\title{
El Camino del Inca en la cuenca superior del río Loa, desierto de Atacama, norte de Chile ${ }^{1}$
}

VARINIA VARELA G. ${ }^{2}$

\section{RESUMEN}

La red vial incaica es la mayor evidencia arqueológica de la prehistoria americana. Ha sido conocida a través de crónicas tempranas, libros, apuntes de viajeros y también por la tradición oral de los pueblos de raigambre originaria. Ellos han conocido su existencia y uso desde los tiempos "mítico-históricos" del Inca. Este trabajo quiere dar a conocer los avances arqueológicos realizados en un pequeño segmento de la red vial incaica, ubicado en las quebradas altas de la provincia de El Loa, en la II Región de Antofagasta (Chile), a partir de un enfoque etnoarqueológico.

\begin{abstract}
The inca road is the must important archaeological evidence of the precolumbian America. Its been described in early chronicles, books, and travellers notes. Evidence of this road are still present until now in the oral tradition of the original ethnic groups. They know abouts its existence and use, since historical and mythical times of the Inca. By means of a theoretical frame, focus in ethnoarcheology, the aim of this paper is to communicate the new archaeological evidences found in a small segment of the Inca highway, located in the high gorges of El Loa province, inland Antofagasta, Chile.
\end{abstract}

1 Proyectos FONDECYT 1970528, 1000148 y 1011006.

2 Museo Chileno de Arte Precolombino. Casilla 3687, Santiago.

\section{Introducción}

Sin lugar a dudas los estudios monográficos más importantes y completos que se han realizado hasta el momento en relación a la red vial incaica, son los publicados por John Hyslop. En su trabajo de 1992, el autor reúne sistemáticamente una gran cantidad de información a través de fuentes bibliográficas modernas, coloniales, y en especial de sus propias investigaciones en terreno. Sus trabajos incluyeron doce tramos del citado sistema vial, los que abarcaron algunas pequeñas regiones de Argentina, Bolivia, Chile, Perú y Ecuador. Estos tramos fueron ubicados dentro de un mapa general, donde se reconocen los dos troncales hacia el sur del Cuzco, los dos hacia el norte y numerosos caminos secundarios y transversales. Para Hyslop, muchos de los caminos en los Andes son de data preincaica y posteriormente fueron integrados a la red planificada del Inca. Para su investigación definió como camino inca a "...cualquier ruta que exhiba o no elementos formales de construcción, que fue usada en tiempos del Imperio y que estuviera relacionada a edificios y/o asentamientos cuyas funciones estuvieran vinculadas al manejo del Estado Inca." (1992:32). Esta definición descansa en parte en dos hechos: la inexistencia de una técnica de construcción inequívoca que los defina y en una buena evidencia histórica. Dentro de esta caracterización el autor omite en forma intencional todas aquellas rutas preincaicas que no fueron utilizadas por el imperio, y aquellos caminos locales que pudieron haber funcionado en época del Tawantinsuyu, pero que no fueron usados para asuntos del Estado.

Por otro lado, cuando Hyslop hace explícitas sus 
reservas hacia el uso de las anotaciones de informantes locales, argumentando que en muchas partes de los Andes existe "...una tendencia a denominar 'inca' cualquier senda o camino antiguo, término que en general puede tomar el significado de muy "antiguo,"' sin embargo señala también que un campesino indígena puede dar datos muy precisos y detallados.

\section{Metodología}

La revisión bibliográfica de cronistas, viajeros y arqueólogos, permitió la recopilación de antecedentes para una primera aproximación a la caracterización y funcionamiento del camino del Inca en el norte de Chile. Conjuntamente, el estudio de fotografías aéreas, mapas y cartas geográficas del Loa Superior nos aportaron en la observación de la topografía, los caminos y senderos demarcados y la toponimia. En este sentido, el significado de los nombres de los lugares, es con frecuencia una referencia útil para sugerir la presencia incaica. Así observamos en distintos mapas (Bertrand 1885 en adelante) y cartas geográficas, nombres quechuas y españolizaciones, tales como Atahualpa, Chac Inga, Copacoya, Incahuasi, Los Altos del Inca, Portezuelo del Inca, etc.

Otra fuente de gran importancia se constituyó en la historia oral, donde los relatos relacionados al tema de los senderos fueron analizados bajo la perspectiva de la organización de una prospección arqueológica. Se abordó en forma sistemática y prudente la memoria histórica de los descendientes de los pueblos originarios con la convicción y experiencia de que es un conocimiento muy valioso y útil para la interpretación arqueológica, en este caso específico para la caracterización, funcionamiento y significación ideológica y simbólica de los caminos dentro del Tawantinsuyu (Castro y Varela 2000). Luego de cruzar las informaciones obtenidas a través de la arqueología, cartografía, etnografía y etnohistoria-historia se realizaron breves reconocimientos en senderos y caminos, los que fueron acompañados de registro fotográfico, recolecciones superficiales y de localización de puntos con la utilización del Sistema de Posicionamiento Geográfico (GPS).

\section{El Camino del Collao}

Ideológicamente el Inca

"asociaba sus caminos con la división conceptual del espacio y la sociedad. Los caminos constituian un medio de concebir y expresar su propio concepto de una geografía cultural" (Hyslop 1992: 19).

Son numerosos los documentos etnohistóricos que nos dan noticias acerca de la red vial incaica y de la división de los cuatro caminos que salían del Cuzco a cada una de las cuatro particiones del Imperio, entre muchos están Pedro Pizarro (1986[1572]), Guamán Poma de Ayala (1993 [1616]) y Vázquez de Espinoza (1948[1629]: 516):

"1499. De la ciudad salian quatro Caminos Reales principales para las quatro partes de su imperio segun los quatro vientos; El que salia a la parte del norte hazia Lima Quito y demas prouincias de abajo, llamaban Chinchasuio. A el que salia por la parte del poniente a las provincias Aymaraes, Collaguas, Condesuios, y Arequipa, llamaban Cuntisuio, y los Españoles Condesuios, Al que salia por la parte del sur al Collao, y a todas las prouincias que va a La paz, Charcas, Potosi, con todas las prouincias de arriba, y Reyno de Chile llamaban Collasuio, que los Españoles llaman Camino del Collao. A el camino que salia al oriente llamaban Antisuio, que los Españoles llaman Camino de los Andes" (p. 516)

En relación al camino del Collasuyu, Raffino señala que:

"There are two principal roads, both essentially north to south running from Cuzco either side of the cordillera: the mountain road wich traverses the Bolivian altiplano and then into northwestern Argentina; and the coastal road from Cuzco via Arica crosses the Atacama desert and into the temperature regions of the Chile as far as the Cachapoal Valley. Apart from these there are various alternative trans-andean routes linking the 2 dorsal roads and a number of other fronterier roads" (1995: 38)

Al respecto A. R. González (1980: 43) remitiéndose a los estudios de Strube acerca del camino del inca en Noroeste argentino (NOA), plantea que 
los caminos principales o reales tenían por objeto relacionar las diferentes regiones de la provincia y conducir a Chile, y por tanto, de éstos partían ramales o caminos secundarios que atravesaban los principales pasos cordilleranos como por ejemplo: Cerro del Potro, Portezuelo del Inca y el Paso de Valeriano. El camino real del NOA correría por el valle Calchaquí hasta el paso de San Francisco para llegar a Copiapó, y este mismo tendría otro ramal principal paralelo que seguiría hacia el sur por La Rioja, Fátima, San Juan hasta el paso de Uspallata. Al mismo tramo se refiere Raffino (1995) que seguiría desde Calchaquí a Yocavil, Hualfín, Abaucán y valle de La Troya al Este del valle de Copiapó.

Núñez (1981) y Santoro (1983) señalan que según las fuentes etnohistóricas el camino costero que se extendía desde Tumbes por toda la costa desértica del Perú, se internaba en el Collasuyu por el desierto del norte de Chile, hacia los pies de las altas montañas, eludiendo las inhóspitas condiciones desérticas. Más específicamente Núñez señala, "...para internarse en el desierto del norte de Chile por las quebradas de Tarapacá y seguir por el despoblado de Atacama para unirse al otro camino en Copiapó" (1981: 51). Por su lado Santoro (1983) analiza un tramo de $130 \mathrm{~km}$ de largo, de un camino que une Tacna con el valle de Codpa, en la localidad serrana de Socoroma, y que correspondería a un segmento del mismo camino real que atravesaba las tierras bajas del Collasuyu.

\section{Antecedentes del camino del Inca en Atacama}

Por las notas de Bertrand (1885), Le Paige (195859), Mostny (1949), Muñoz (1894), Niemeyer y Rivera (1983), San Román (1896), entre otros, sabemos que el tramo más conocido del camino del Inca en la II Región, es el que une San Pedro de Atacama con Copiapó (Figura 1). En la década de los ' 80 , tuvieron lugar dos expediciones arqueológicas a este segmento en las que participaron Niemeyer, Hyslop, Núñez y Rivera, entre otros. La primera expedición abarcó de Peine a la aguada de Puquios y la segunda de allí a la quebrada El Juncal. El resultado de estas expediciones fue el reconocimiento de varias estructuras tipo tambo, chaskiwasi, refugios y paravientos. Los sitios más importantes detectados fueron los tambos de Peine, Meteorito, aguada de Puquios, río Frío y

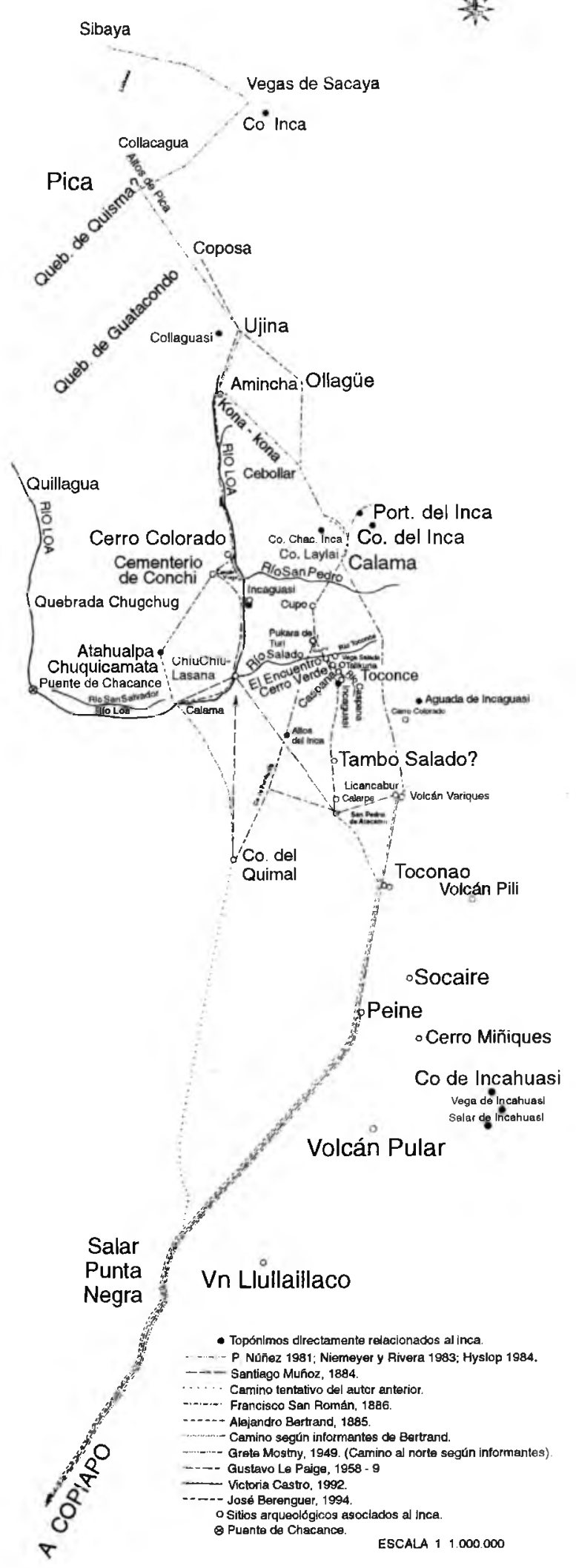

Figura 1. Red vial incaica, norte de Chile 
quebrada de Vaquillas y los tambillos el Cráter y Neurara (Hyslop 1984 y 1992, Hyslop y Rivera 1984, Niemeyer y Rivera 1983 y Núñez 1981).

Otro segmento descrito es el enunciado por Mostny (1949) en las ruinas del Pukara de Turi, a cuya información se suman relatos recopilados por la misma investigadora, los que informan que el camino seguiría hacia el norte por Cebollar en la ribera occidental del Salar de Ascotán, Miño, Aguada y Pampa de Ujina; al Oeste del cerro Pabellón del Inca, Cerros de Quelcocha y de Quisma (?) por la parte alta de la Laguna del Guasco, Pampa de Sacaya y entre los cerros Piga, Lupe Grande y Lupe Chico a Sibaya. Le Paige (1958-59 :79) hace mención del dominio incaico en la zona atacameña señalando que éste

“...se manifestó en Atacama, no por una nueva red de caminos ya que éstos existían, sino por un perfeccionamiento y una orientación centralista."

En el mismo trabajo describe la red de caminos del área, que en uno de sus segmentos se correspondería con el tramo prospectado durante el presente estudio.

Posteriormente, Castro (1992: 146) refiriéndose a nuevos registros de sitios incas en la región del Loa, subregión del río San Pedro, anota el camino de Colana con cierta prudencia en su asociación con el Inca, localizándolo a $4.200 \mathrm{~m} . \mathrm{snm}$ y caracterizándolo como

"...un camino de aproximadamente $2 m$ de ancho, despejado de piedras con tramos empedrados y obras de retención. El camino asciende hacia las pampas y portezuelos limitrofes con Bolivia y hacia el sur enfrenta el abra de Cupo y la hondonada que se forma entre el cerro Chao y Paniri, pudiendo alcanzar por esos puntos hasta Turi, en la subregión del río Salado."

Finalmente, Berenguer (1994) recorre un tramo de unos $10 \mathrm{~km}$ entre la quebrada de la Cañada y el sitio Cerro Colorado 1, al W del cauce superior del río Loa (Castro 1992).

Asimismo, cabe mencionar la posible existencia de un puente incaico en Chacance, Loa Medio. Aquí “...se reunen los dos brazos con caudal competente de agua más hondo que la estatura de un hombre, por cuya causa hay dos puentes formados de fajina sobre pedestales de piedra" (Cañete y Domínguez 1974[1791]: 245-6; Nota de Horacio Larraín: "puentes de fajina", construidos con haces de rama y gramíneas resistentes, amarradas fuertemente entre sí.).

\section{Nuevos aportes sobre el Camino del Inca en el desierto de Atacama}

Entre 1997 y 1998 se prospectó un tramo del camino del Inca que probablemente sería parte de una ruta troncal que vendría desde territorio boliviano, pasando los límites políticos actuales, integrando el camino de Colana por el norte (Castro 1992), el abra de Cupo, la pampa de Pacaitato cercana al sitio Topayín del Período Intermedio Tardío, el Pukara de Turi, la confluencia de los ríos Caspana y Salado, la estancia de Pila, confluencia del Caspana con el Pedregal, la instalación incaica de Cerro Verde y el pueblo de Caspana. De allí el camino seguiría a San Pedro de Atacama, pasando por la quebrada de Incahuasi, Altos de Lari, el río Likan o Salado, y alrededores de los pueblos de Río Grande y San Bartolo (Figuras 1 y 2).

Colana

Empezando de norte a sur, fueron infructuosos los deseos de incorporar en este tramo la supuesta posta incaica de la quebrada Chac-Inga señalada por Bertrand (1885) y cuya traducción literal sería "puente del Inca." De igual modo, la prospección pedestre de Cupo-Colana fue fallida debido a la existencia de numerosos campos minados, sólo algunos señalizados con un pequeño cartel circular sin inscripciones. Entonces, cruzamos el abra de Cupo por un camino en muy mal estado para llegar a una gran explanada de vegas secas, polvorientas, blancas y donde el viento se elevaba en grandes y estéticos remolinos. Nos situamos entre los Ojos de San Pedro y las vegas de Inacaliri, hacia el norte teníamos los cerros de Lay-Lay y hacia el Este los de Colana, y en la pampa en esta última dirección una instalación modular de Codelco. En la explanada vimos varios de aquellos pequeños letreros. Una vez en la quebrada de Colana, que separa los cerros de Lay-Lay con el cordón homónimo, continuamos hasta donde el 


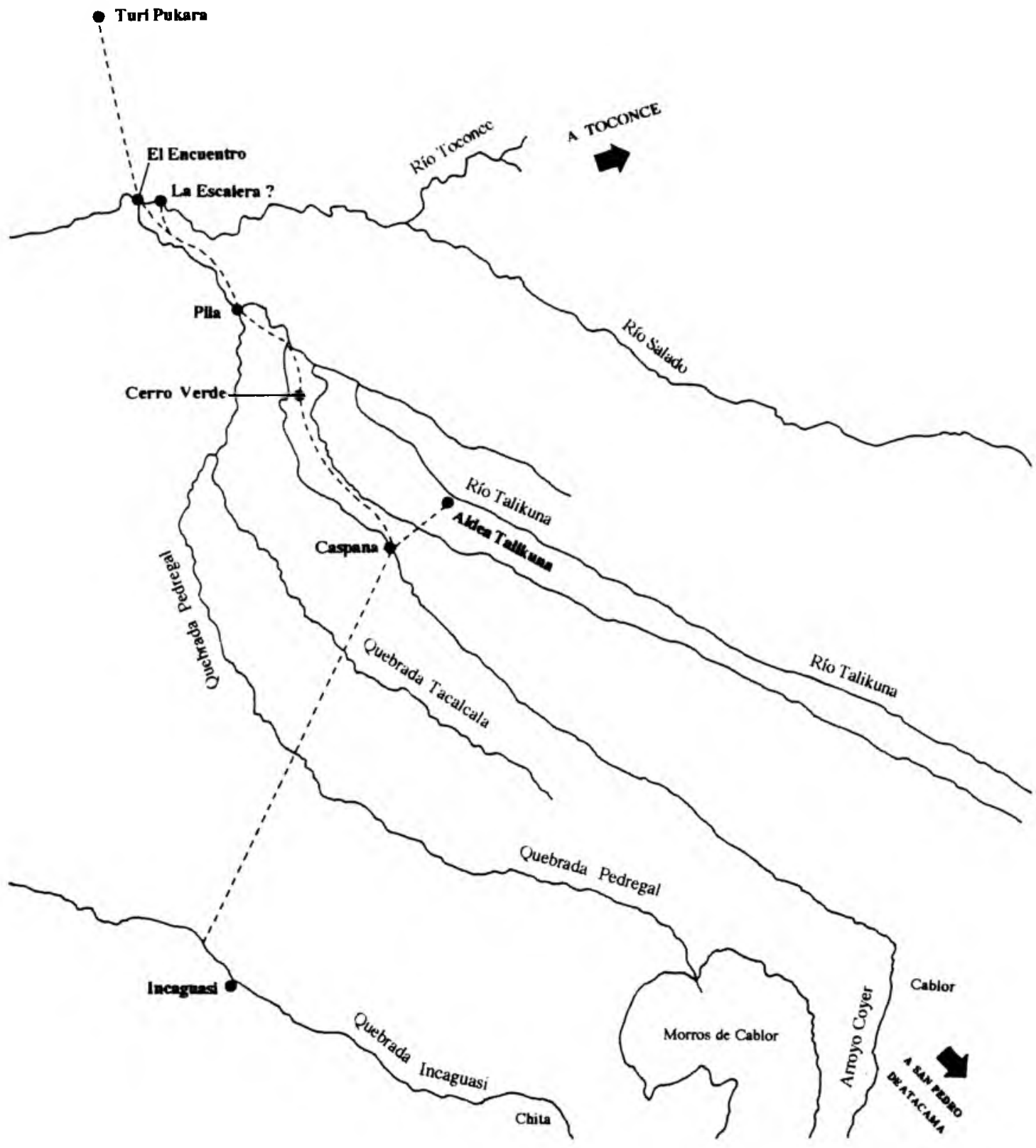

Figura 2. Prospección arqueológica realizada en 1997 
camino se corta por un gran portón de fierro señalizado Codelco. Continuamos a pie siguiendo aguas arriba por la quebrada. Por ambas vertientes observamos la existencia de postación que nos sugirió no salirnos de estos deslindes. Toda el agua de la quebrada está entubada y observamos muy poca flora y fauna. En la vertiente norte e inmediatamente al costado del camino vehicular, nos encontramos con la Cueva Chica que en la carta geográfica estaría indicada en la vertiente opuesta. Aquí vemos las paredes tiznadas del alero, con una profusión de petroglifos entre los que destacan figuras identificadas como "vulvas." Sobre y a los costados de ellas hay otras irreconocibles, fracciones de camélidos e inscripciones de 1952, 1954 y 1966 . De la cerámica de superficie reconocimos aquella roja alisada de Turi (Varela 1992), fragmentos de pasta con mica sin y con revestimiento rojo, semejante a la cerámica del cementerio Los Abuelos de Caspana y un fragmento de aspecto temprano con antiplástico muy grueso. $\mathrm{El}$ escaso material se mezcla con basura subactual y moderna. Dos estructuras adosadas a la pared del alero, de muro simple y con gran cantidad de argamasa entre las piedras, terminan por caracterizar la cueva. Seguimos subiendo hasta ver una bifurcación y allí tomamos el ramal menos transitado que se dirige hacia el norte por una fuerte pendiente de arena y ripio. En superficie, aislado, encontramos un fragmento cerámico altiplánico Tardío (Hedionda local sensu Uribe 1996). Llegamos hasta un portón similar al del inicio, lo cruzamos y subimos la última abra. Al costado NO vemos otro camino que nos llama la atención, señalizado en ambos costados por hileras de piedras medianas a grandes y cubierto completamente de arena. El sector donde nos encontramos ya está fuera del terreno de Codelco, no hay señalizaciones y consideramos arriesgado distanciarnos del sendero vehicular. De esta abra miramos hacia el norte la pampa de la Cachimba y el portezuelo que comunicaría esta explanada con la septentrional pampa de la Apacheta. En dirección contraria a este camino registramos un pequeño sitio, conformado por tres estructuras de piedra, de planta subcircular, bajas, con diámetro entre los 2,3 y 1,8 $\mathrm{m}, \mathrm{y}$ adyacentes a afloramientos rocosos. La distribución de los desechos abarcan hasta unos $6 \mathrm{u}$ $8 \mathrm{~m}$ del camino. Lo denominamos sitio Del Vidrio por la gran cantidad de trabajo de desbaste encontrado en esta materia prima. Además, ob- servamos alfarería del Intermedio Tardío, Tardía, Colonial temprana, loza y etnográfica. Nos devolvemos por el mismo camino hasta la bifurcación y retomamos el que mostraba mayor tránsito. Este se interna quebrada adentro desdibujándose y donde comenzamos a ver numerosas estructuras, un asentamiento tipo estancia, entre la que destaca una habitación con el vano y dintel intacto, con poyo interior y que recuerda a algunas estructuras de Aldea Talikuna en Caspana. Encontramos material prehispánico tardío y moderno en superficie. Inmediatamente al Este, donde las estructuras se hacen de mayor tamaño, observamos un taller lítico, cuya principal materia prima es la calcedonia. Aquí la curiosidad nos atrapa y decidimos guiarnos por las huellas dejadas por el paso de las llamas para adentrarnos quebrada arriba, donde nuevamente ya no existe la protección de Codelco. La quebrada se comienza a estrechar fuertemente donde vemos las últimas estructuras tipo corral. La pendiente se hace fuerte y en el costado sur de la quebrada se nos presenta la Cueva Grande, señalizada en la carta geográfica correctamente. El techo está muy desmoronado, parte de las paredes muy tiznadas, se ve pintura roja en un sector bajo pero fue imposible reconocer alguna figura. Unos pocos metros más arriba vemos un primer tramo de camino empedrado, en muy malas condiciones de conservación. Su ancho no supera los $3 \mathrm{~m}$ y ocupa buena parte del ancho de la base de la quebrada. En partes ésta se estrecha tanto que el camino desaparece por el correr de las aguas lluvia, en otros sectores donde se ensancha en ocasiones sube pequeños lomajes para volver a caer al cauce. Observamos en varios otros puntos muros de contención que afirman la recta del camino que se conduce en "SSS" aguas arriba. Ya eran pasadas las seis de la tarde, cuando llegamos a un sector donde se ensancha la quebrada, y donde se observa una pendiente arenosa que permite un paso orientado al norte, sin embargo la quebrada sigue en dirección $\mathrm{SE}$, donde el perfil de ella deja ver uno de los cerros del cordón de Colana marcado por caminos rectos diagonales que suben hasta casi la cima. En estos caminos se alcanzan a ver muros de contención de muy buena construcción que en conjunto con lo que hemos recorrido, nos hacen pensar más bien en un camino llaretero que en un tramo de los caminos incaicos. Nos devolvemos sin haber unido en terreno, el camino de la quebrada con aquellos o 


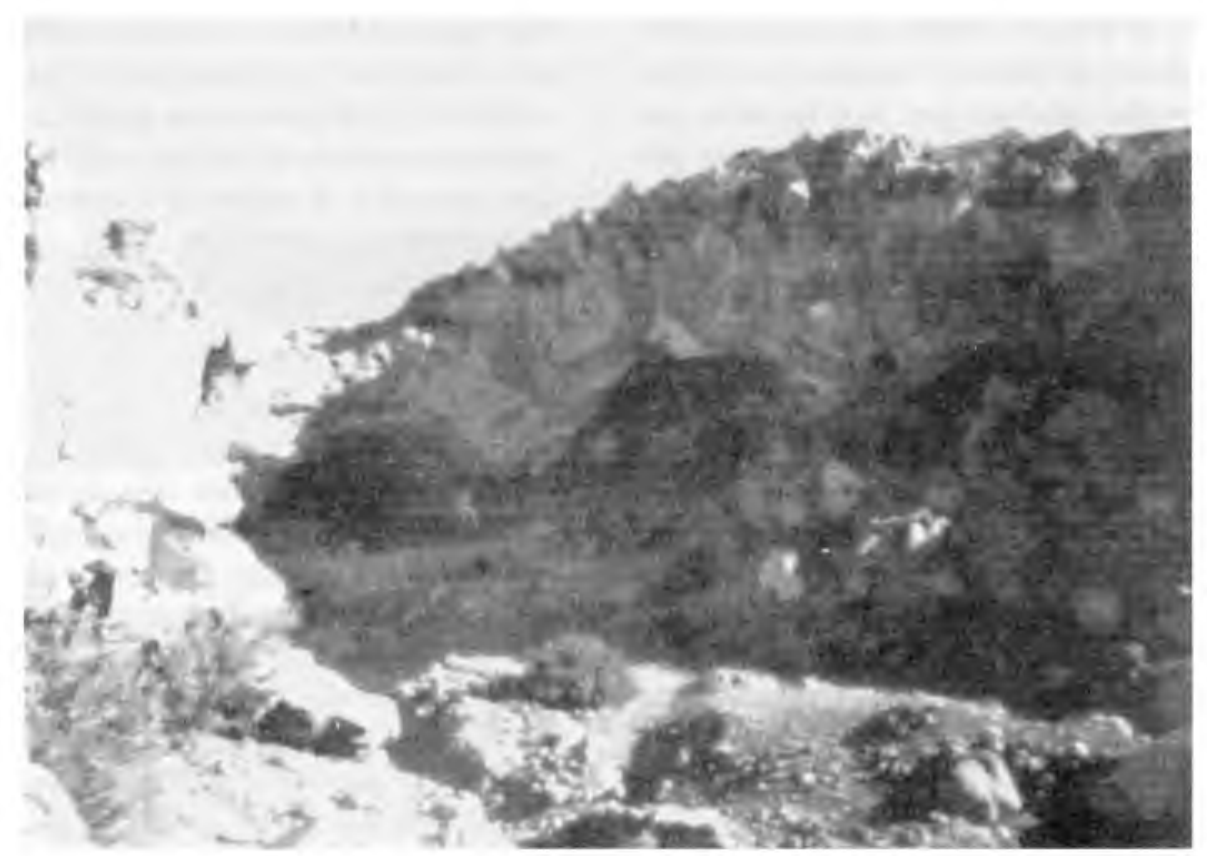

Figura 3. Alero y taller lítico del sitio Ojos de Cupo

aquel que vemos en el cerro de Colana.

\section{Cupo-Fort Henry-Pacaitato}

En la vega de Turi, el camino que viene del Pukara al norte continúa hacia el ojo de agua y de allí a Cupo, pasando por Topayín, precisamente por la vega de Pacaitato. El camino de vehículos hasta su bifurcación con el que va a Paniri, asentamiento agrícola del Intermedio Tardío, está sobre un arenal y coincidiría con el camino del Inca. De allí hacia el abra de Cupo sigue muy pedregoso según nos han señalado y nos señalarían de igual manera en Cupo. Una vez aquí, buscamos alguién para preguntar acerca de unas pinturas rupestres que en Santiago habíamos conocido a través del padre mercedario Jorge Astrosa, el entonces director del museo de la congregación, que algunos años residió en Calama. Siguiendo las ejemplares indicaciones de una viejita del lugar, encontramos las nacientes de la aguada que riega los cultivos de Cupo. En una pequeña entrada de la quebrada hay tres aleros altos con techos de lajas andesíticas, muchas de ellas fueron ocupadas para la confección de palas líticas, de formas semejantes a las que conocemos en la región (Uribe y Carrasco en este volumen) (Figura 3). Aguas abajo y a pocos metros, sobre la ladera izquierda comenzamos a ver numerosos aleritos que se van sucediendo, cada uno con un pircado exterior. Poseen ocupación prolongada desde el Intermedio Tardío hasta tiempos actuales. Distinguimos casi 30 paneles de arte rupestre, petroglifos de estilo Kalina (Alto Loa), pinturas en rojo semejantes a las del río Salado, caravaneros en colores amarillo, verde y rojo, petroglifos modernos de camiones que me recuerdan los hallados en el Alto Loa, cabezas de llamos con cuerpo serpentiforme en color naranjo, figuras serpenteantes circunscritas en un subcírculo semejantes a las de Turi y el Salado, y unos pocos petroglifos de camélidos rígidos en técnica de picoteo que hemos asociado con la presencia incaica. Nuestro recorrido por los campamentos de Los Ojos de Cupo nos cobró toda la tarde, y el regreso fue en vehículo, dejando pendiente el reconocimiento a pie de este tramo. Pasando el camino que corta hacia el pueblo de Cupo, vemos otro ancho que más adelante se nos vuelve a cruzar. La viejita de Cupo nos había señalado éste para bajar hasta las vegas de Pacaitato y luego a Turi, "viene de San Pedro (Inacaliri)", nos dijo. El camino vehícular Turi-Cupo pasa por el NO 
del cerrito de Topayín, y entre éste y unas estructuras de piedra de planta rectangular que en ocasiones pasadas quisimos ver. Nos bajamos para recorrer el lugar, algunas de las estructuras presentaban radier que había sido roto ex profeso. En superficie, la cantidad de latas, vainas de fusil, vidrios y unas trincheras militares excavadas sobre un pequeño promontorio tras las estructuras, nos delatan que estas construcciones debieron pertenecer a las instalaciones del antiguo Fort Henry, guarnición del ejército. Otras estarían en los faldeos mismos del cerro Topayín. En el promontorio recolectamos cerámica etnográfica y roja alisada de Turi, en los sectores más bajos también hallamos vidrio lila, cerámica altiplánica tardía, una preforma de punta de proyectil, algunos fragmentos de malaquita y basuras múltiples.

\section{Turi-El Encuentro-Pila}

Salimos antes de medio día de la casa de María Berna en las estancias de los baños de Turi. El camino, según señala Virginia, hija de María, es recto y está muy borrado, como apenas lo distinguimos en la carta aérea. Subimos al Pukara de Turi por la quebradita del oeste, frente a los corrales de Virginia y en la entrada a la cancha de la kallanka del sitio, nos señala un camino que habría hecho Domingo Berna para traer agua desde frente de sus corrales. Este camino bordea y llega por detrás del gentilar, justo atravesando el camino inca indicado ya por Mostny en 1949 (Figura 4). Seguimos hacia el sur donde se va desdibujando el camino y en la parte mejor conservada se aprecia el despeje del terreno de las rocas más grandes, quedando éstas alineadas en ambos bordes. Bajamos por un sector más o menos despejado y que está cubierto de arena fina y blanca hasta el plano. Adelante no se distingue camino alguno, aquí la superficie es arenosa y corre viento gran parte del día. Virginia señala que debemos llegar en línea recta a una "llave de la cañería", desde donde saldría el camino tropero que va hacia El Encuentro. Ciertamente, aquí el camino presenta cierta socavación en el sustrato arenoso, es estrecho y en ocasiones se bifurca para volver a encontrarse más adelante. En las partes más anchas no sobrepasa los $1,8 \mathrm{~m}$. Virginia señala que los burros al caminar van dejando una huella más profunda que las llamas, haciendo pequeñas ondulaciones que señalan los pasos, mientras que las lla- mas dejan el camino con una concavidad pareja en el centro. Lo seguimos hasta llegar a un leve alto donde distinguimos una acumulación de piedras desmoronada. El camino es débil, de sustrato aún arenoso y se ensancha levemente mientras subimos hasta donde encontramos otra acumulación baja y derrumbada, con unas piedras que sugieren dudosamente otras dos estructuras pequeñas. En este hito encontramos un fragmento de cerámica de pasta colada que hemos incluído dentro de la familia altiplánica asociada al Inca. Hacia el Este, en la segunda cota de mayor altura, vemos otras cuatro estructuras semejantes, desordenadas y derrumbadas. Hacemos un reconocimiento sin observar material cultural en superficie. Seguimos el trazado, pasando por la única quebradita de nuestro itinerario Turi-El Encuentro. Por aquí bajó el agua, dejando evidentes huellas de su paso. El camino está borrado y lo retomamos una vez pasando la quebradita, cuando el terreno nuevamente se hace plano. Más adelante cruzamos un antiguo sendero vehicular, paralelo a una antigua tubería, es ancho, recto y está muy cubierto de arena. Unos cientos de metros más adelante pasa el actual camino de la cañería Toconce-Ayquina. Unos 15 a $20 \mathrm{~m}$ antes de llegar a la "huella" Toconce-Ayquina, como los lugareños llaman al camino vehicular, vemos dos hitos o acumulaciones de piedras nuevamente derrumbadas, distantes unos $10 \mathrm{~m}$ entre sí y por donde pasa el camino por el que vamos. Nuevamente, no encontramos material cultural en superficie. Seguimos ahora unos pocos metros por el camino de autos, para retomar hacia un costado el sendero que baja al río Salado. Desde aquí se ve "El Algarrobal" de la confluencia de este río con el Caspana y bajamos por un estrecho sendero que dibuja un zig-zag, con un rústico muro de contención. Cruzando el río, hallamos petroglifos de dos llamos lineales rígidos, delante de uno de los paneles más grandes y abigarrados del Encuentro (Gallardo et al. 1999). Ahora el camino sube por la ladera contraria de la quebrada, haciéndose muy notorio, blanquecino y desgastando la roca ignimbrítica. Antes de llegar a la cima el camino corta una estructura tipo corral. No hay material cultural en superficie. Continuamos hacia la cima por este marcado camino que en ocasiones fácilmente alcanza los $5 \mathrm{~m}$ de ancho. Llegamos a un encuentro de caminos, donde uno baja hacia la quebrada del Salado y pareciera coincidir con una 


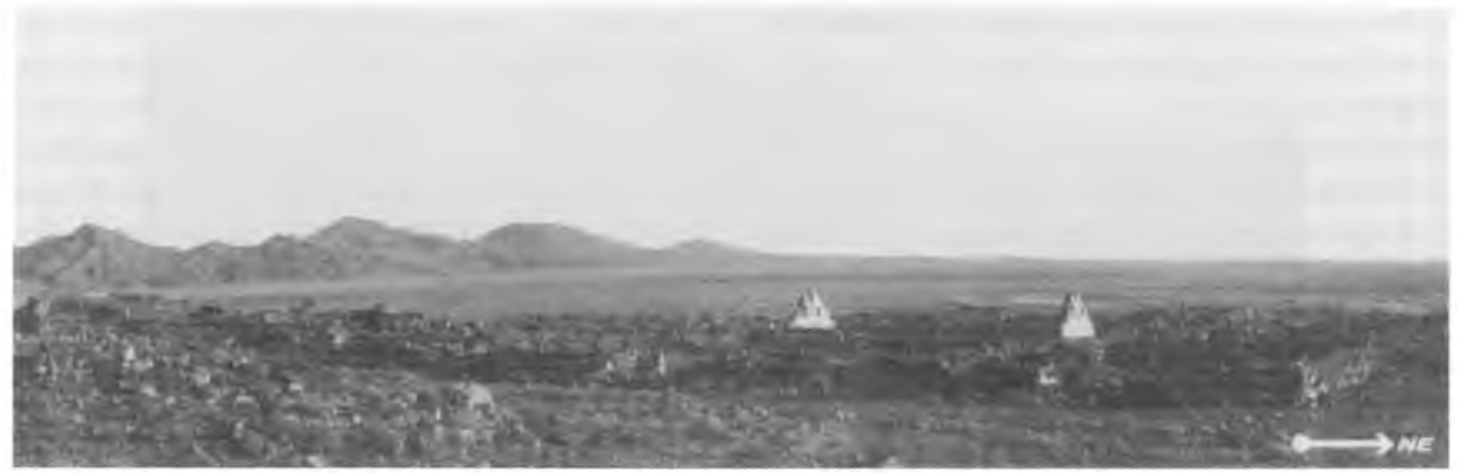

Figura 4. Camino detrás de la cancha y kallanka del Pukara de Turi

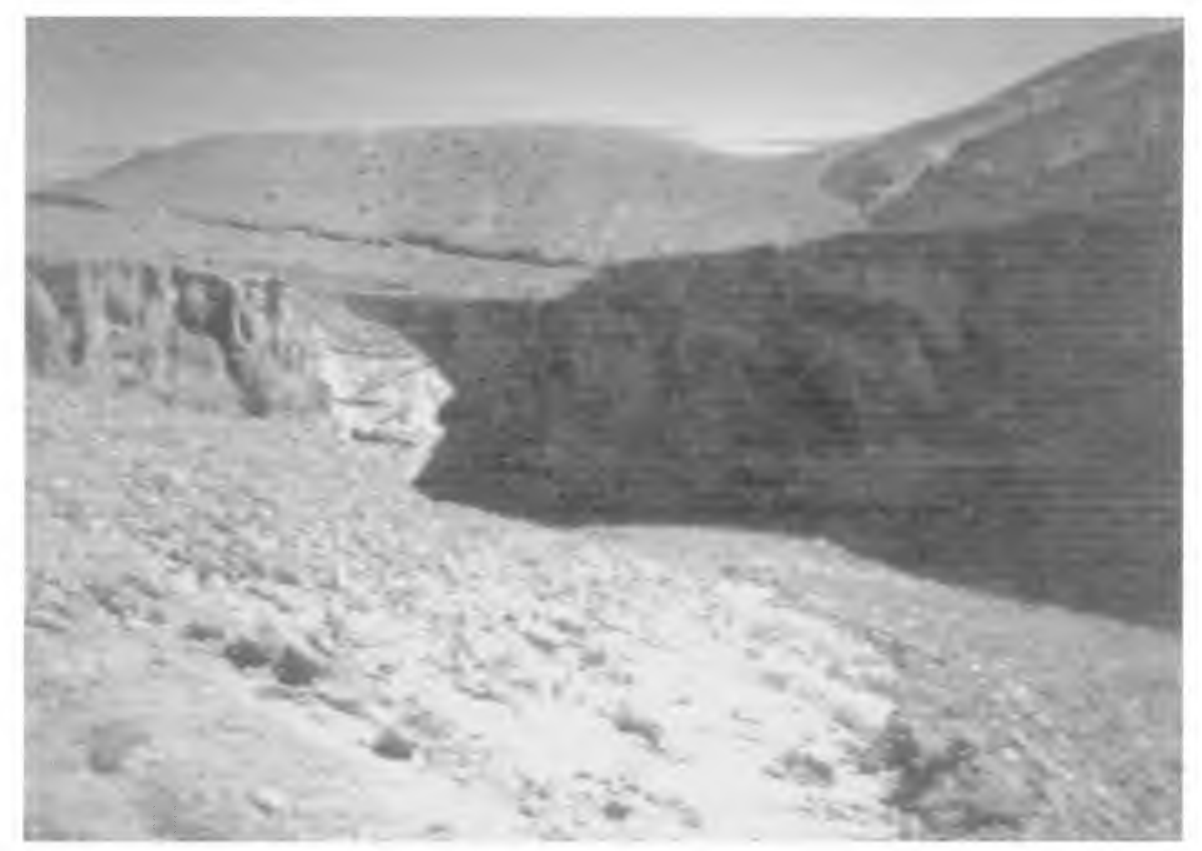

Figura 5. Bajada en zig-zag del río Salado

escala en zig-zag, con un espectacular pircado que después podríamos identificar tentativamente como Tchapolkolo. Seguimos camino hacia Pila, por un trazado recto $y$ ancho, que se va volviendo arenoso. A unos $12 \mathrm{~m}$ pendiente abajo, hacia el Salado, registramos restos de un muro de aproximadamente $8 \mathrm{~m}$ de largo en dirección E-W y completamente derrumbado que señala un terraplén. Tampoco presenta material cultural en superficie. Finalmente, llegamos por el camino a la Capilla de Pila, hoy en mal estado de conservación y con cerámica, mortero, deshechos líticos y basura ac- tual en superficie. Su vano de entrada está abierto hacia los $42^{\circ} \mathrm{NE}$.

\section{Tchapolkolo 3 -Pila-Cerro Verde-Caspana}

Aproximadamente a $1 \mathrm{~km}$ aguas arriba del Encuentro Salado-Caspana bajamos por la "escalera" de Tchapolkolo. Esta bajada aprovecha de piso un afloramiento rocoso del talud de la quebrada.

3 Se ve la necesidad de corroborar este topónimo en un próximo terreno. 
Sobre la roca se han elevado muros de contención que dibujan un zig-zag hasta llegar al nivel del río (Figura 5). La anchura máxima de cada uno de estos "escalones" es de aproximadamente $6 \mathrm{~m}$ y la mínima de $3 \mathrm{~m}$. El pircado es de grandes bolones y de aparejo celular a rústico, sin embargo a distancia se observa como un conjunto de gran factura, y está cortado por un muro de contención que sostiene una cañería y el camino vehicular actual. Pasando el río comenzamos a subir por un camino labrado en la roca ignimbrítica, hacia un costado hay una pequeña estructura en "U" con un pircado bajo de $55 \mathrm{~cm}$ de altura y abierta a los $45^{\circ}$ NE. No hay material cultural en superficie. Seguimos el camino en " $S$ " y junto al costado Este registramos una acumulación de piedras de $1 \mathrm{~m}$ de diámetro y $90 \mathrm{~cm}$ de alto. El camino continúa ascendiendo recto e inclinado y en superficie vemos uno que otro fragmento rojo alisado de Turi y partes de herraduras de mulas. Llegamos hasta donde hay un pequeño alero que mira al norte, en su interior hay estiércol de mulares y no se ve material en superficie. Unos metros más arriba del alero converge este camino con el que se inicia en El Algarrobal. Desde allí continuamos hacia Pila. Al costado oeste del camino se ve un promontorio o pequeño cerrito negro, en cuyos faldeos hay escasos fragmentos de cerámica Ayquina y arriba algunos de filiación altiplánica Tardía (Uribe 1996), pero no hay ningún tipo de estructura. Continuamos hasta la Capilla de Pila donde el camino baja a la terraza ribereña de la confluencia del Caspana y Pila, como mencionan los lugareños a la Quebrada del Pedregal, por un sector de arenal donde hay gran cantidad de desechos (Figura 6). En la margen Este del camino hay un panel con una gran llama y una pequeña ave en su interior (Gallardo et al. 1999:63). Una vez abajo, se intersecta con la huella vehicular que parece cortar la estancia de la señora Salvatierra. Ahora la única vía alternativa es continuar por dicho camino, cruzar el agua y pasar el arte rupestre "moderno" que incluye al personaje Condorito, hasta la mitad de la subida donde el camino antiguo se aparta siguiendo paralelo al de vehículos y se interna por el talud de la quebrada del Caspana, hacia la siguiente confluencia de éste con el río Curte. El camino conduce a una estancia actual, situada en la mitad del talud, y desde allí seguimos hasta el encuentro de ríos, hacia el sitio de Cerro Verde. Bajo el sendero del Curte y enfrentando la subida del camino que va a Toconce vemos una apacheta que mide $1 \mathrm{~m}$ de diámetro y 1,6 de alto. En las inmediaciones recolectamos cerámica YaviLa Paya y roja revestida de Turi. En la cima de la otra ribera del río vemos otra apacheta de dimensiones semejantes. En Cerro Verde el camino tiene un ancho de casi $2 \mathrm{~m}$ y se dibuja muy desgastado en línea recta hacia arriba. En el costado oeste encontramos otra acumulación de piedras de 90 $\mathrm{cm}$ de diámetro y $70 \mathrm{~cm}$ de alto, desde allí se mira la apacheta del otro lado de la quebrada. Al mismo costado del camino y frente a las construcciones subactuales que Julián Colamar llamara " $\mathrm{La}$ Iglesia" y donde llega el camino vehicular Caspana-Cerro Verde, encontramos otra más de estas estructuras de $60 \mathrm{~cm}$ de diámetro y $50 \mathrm{~cm}$ de altura. Seguimos por la huella hasta donde hay dos ramales diagonales, el de mano derecha vuelve unos pocos metros más adelante a empalmar con el de vehículos y el otro continúa como sendero hacia una quebrada seca. Tomamos por este último, que sigue paralelo a la quebrada a una cota más bien alta. Adelante encontramos un pequeño muro de contención del camino de 2,4 m de largo y $45 \mathrm{~cm}$ de ancho. Y unos metros aún más adelante hay otro de similares dimensiones. Continuamos camino hacia Caspana, hasta dos conjuntos de piedras amontonadas de 1,3 y 1,2 m de diámetro, dispuestos uno a cada lado del camino y distante entre sí 1,2 m. Hay poco material cultural en superficie, cerámica roja revestida Inca-local y una moneda de los años setenta. Cientos de metros más adelante el camino empalma nuevamente con la huella que llega al Pueblo Viejo de Caspana.

Cementerio de Los Abuelos-capilla del alto de Caspana-Incahuasi

El gran camino de subida por el farellón sur de la quebrada de Caspana es el que posee mayor trabajo de ingeniería de todos los recorridos. Actualmente este camino parte del Pueblo Viejo de Caspana, pasa cortando el Cementerio de Los Abuelos, por el tercio superior, y sube sostenidamente en línea recta el talud de la quebrada. Se encuentra libre de piedras, con un sustrato arenoso y su ancho es más o menos regular alcanzando los $3 \mathrm{~m}$. Sobre el cuarto superior de este camino, comienza a asomar el cascajo del suelo ignimbrítico y se observa una escalinata labrada en la roca de pequeños peldaños hoy des- 


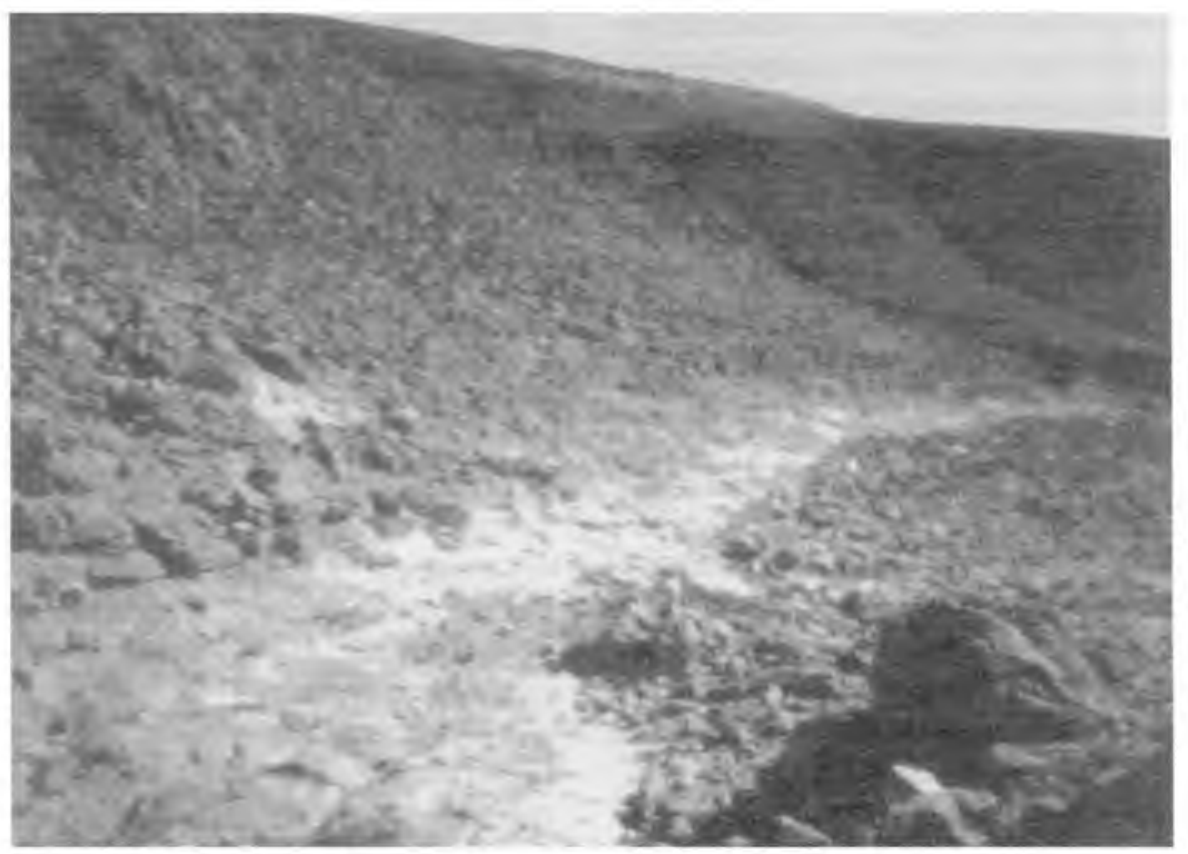

Figura 6. Camino El Encuentro a Pila

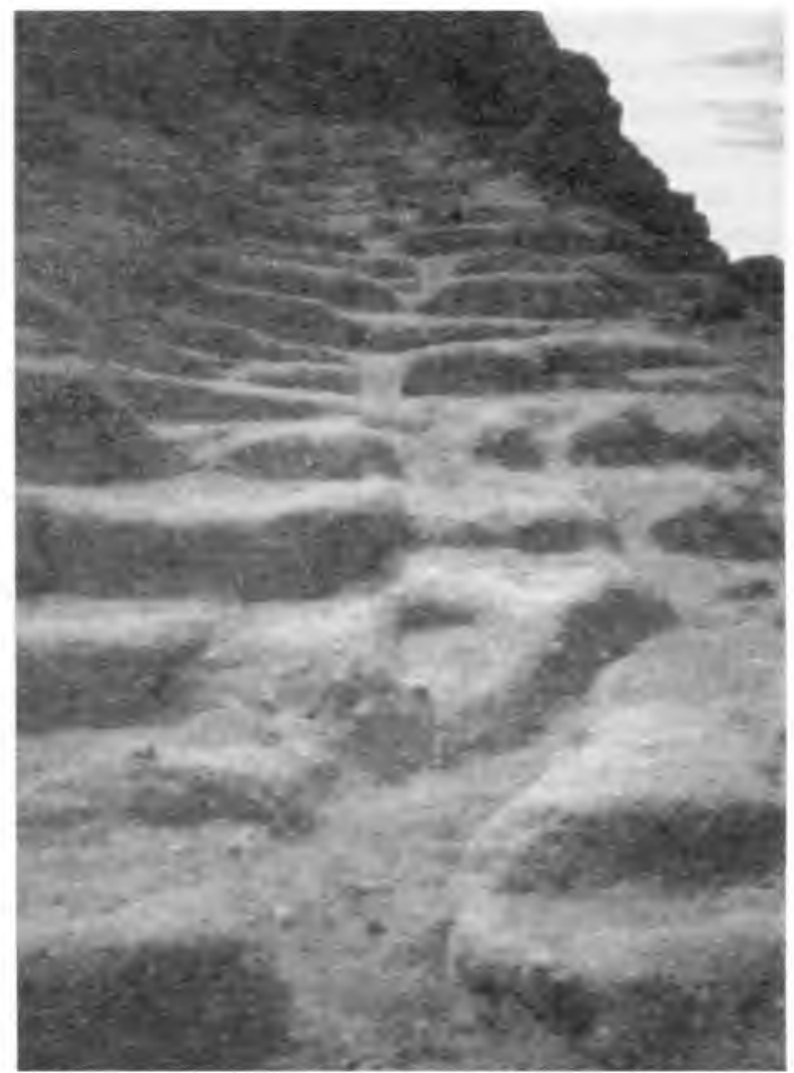

Figura 7. Escalera labrada en piedra, en camino de Caspana al alto de la capilla 
gastados por el tránsito (Figura 7). Después de un viraje de aproximadamente $80^{\circ}$, la superficie se convierte en un camino empedrado que en un vasto trecho necesita relleno y contención para continuar hasta la explanada del alto. Se llega a esta explanada por medio de otra ancha escalinata formada por piedras de regulares tamaños muy bien encajadas. Arriba en la meseta hay una capilla con una gran cancha rectangular y en ella un altar con una cruz, lugar donde hoy peregrinan los lugareños en ocasión de sus festividades, en especial de la Virgen de la Candelaria, patrona de la comunidad. Del vértice SE de la cancha, sale un pequeño sendero que llega hasta el sitio de Aldea Talikuna, aproximadamente a $1.5 \mathrm{~km}$ en línea recta desde la capilla y bajando previamente por la Quebrada Seca. Los lugares por donde se bajan a las quebradas suelen estar señalizados por hitos o pequeñas acumulaciones de piedras. En sentido contrario, hacia Incahuasi el camino está señalizado en la carta geográfica como un sendero y se ve nítidamente en la fotografía aérea. Se cruza y corta en varias partes con el camino vehicular o huella que une Caspana con Chiu-Chiu. En la última intersección de ambos caminos, su ancho es de aproximadamente $2,5 \mathrm{~m}$ y se eleva unos $2 \mathrm{~m}$ por sobre el nivel de la huella. El camino está limpio de piedras, muy marcado, evidenciando un arduo tráfico. En una cantera explotada de liparita blanca y a unos $200 \mathrm{~m}$ al norte del camino vemos una apacheta junto a una estructura en " $U$ ", semejante a la que encontráramos en una prospección de los faldeos de los Morros de Cablor. La abertura de la estructura se orienta en $130^{\circ}$ y al costado de la apacheta hay basura actual quemada. Pasamos por la primera quebrada donde el camino tiene un pircado hacia un costado, que lo recorre más o menos paralelo y luego lo cruza, aquí mide $3,5 \mathrm{~m}$ de ancho y se dirige en $320^{\circ}$ a la quebrada de Incahuasi. Hay una apacheta desmoronada en la margen inmediata del oeste, de $60 \mathrm{~cm}$ de alto y de 1,2 a $1,5 \mathrm{~m}$ de diámetro. Unos pocos metros más adelante y aproximadamente unos $150 \mathrm{~m}$ hacia el norte del camino, encontramos unas estructuras tipo paraviento asociados a dos corrales miniaturas. En los alrededores hay desechos líticos. Más adelante hay otra estructura desmoronada de unos $3,2 \mathrm{~m}$ de largo y sobre el derrumbre hay un pequeño amontonamiento de piedras y numerosos fragmentos cerámicos alisados rojos y grises de Turi que sugieren ser de una misma pieza, quizás producto de una quiebra ritual. Continuando, en el camino se van sucediendo estructuras similares, a cortas distancias unas de otras, una de las cuales presenta alrededor cerámica Ayquina, desbaste lítico y un fragmento de vidrio negro pulido. Otra la observamos en un pequeño bajo arenoso y ocupa las piedras redondeadas del lugar. Hay fragmentos líticos. Intersectando la huella que va hacia el Tatio nuestro sendero se hace también el de vehículos y en la siguiente estructura derrumbada encontramos cerámica decorada negro sobre rojo, quebrada in situ. Para este amontonamiento se ha usado la piedra redondeada escogida del lugar y al continuar seguimos viendo en ambos lados del camino estructuras semejantes y sin material cultural en superficie. Seguimos por este camino hasta retomar el de baquiano, el que sale al SO. Pasamos frente de la estancia de Marta Panire cercana a una pequeña quebradita con agua. El camino sube por la ignimbrita, marcando el sendero hasta una punta, para allí bajar hacia la quebrada de Incahuasi, pero distante del sitio arqueológico y aguas abajo unos $2000 \mathrm{~m}$ aproximadamente. En otra temporada recorrimos el camino que uniera el sitio arqueológico de IncahuasiInca con el segmento anteriormente descrito. Desde el sitio se observa en el talud Este, una subida con algunos quiebres en zig-zag. Para tomarlo debemos pasar el complejo agrohidráulico (Adán y Uribe 1997: 550), cruzar el cauce y llegar a una débil senda de no más de $50 \mathrm{~cm}$ de ancho, con evidencias de uso actual. En frente está el campamento minero actual con dos grandes bloques de roca mineral, negro-verdosa, donde también hay un camino con muro de contención que desaparece circularmente, para seguir la huella por el penón desgastado, hacia aguas abajo. Comenzamos a subir la ladera por un camino poco transitado y entre rocas con cristalizaciones de magnesio, hierro oligisto y hematita en distintos grados de concreción y pureza. El camino sube recto en diagonal para quebrarse en $60^{\circ}$ más o menos y haciendo escalera de la roca natural. Al costado inferior del camino se acumulan las rocas de mayor tamaño y al costado opuesto se ha socavado extrayendo tierra y piedras del cerro. Se devuelve en zigzag dando la espalda a los cerros Cablor y Chita y tras una pequeña curva llegamos al alto. El ancho del camino aquí es de más de $3 \mathrm{~m}$, se despeja de piedras mayores en los costados y comenzamos a ver otras acumulaciones de piedras semejantes a 
las descritas en el primer segmento de este camino. Hacia el SO del mismo hay una estructura mayor desmoronada que en un costado tiene una huella que termina en hitos geodésicos. Junto a estos hitos encontramos un fragmento de mortero hondo, otro entero más burdo y profundo junto con restos líticos variados. El camino continúa por la huella hasta una bifurcación peatonal que continuamos y que en un trecho más lejano vuelve a cortarse por el camino de autos que va hacia la mina de Incahuasi, continuando ortogonalmente sobre un sustrato arenoso con despeje de piedras hacia los costados y que finalmente llega a la misma estancia de Marta Panire.

\section{Conclusiones y proyecciones}

Hemos unido mediante antiguos caminos los sitios arqueológicos incas del territorio comprendido por el río Salado, Turi-Cerro Verde-CaspanaIncahuasi, siguiendo una dirección general aproximada NO-SE, y logrando así un primer reconocimiento de la red vial incaica en la zona. El camino atraviesa una geografía de quebradas altas, entre los 3.250 y $3.500 \mathrm{~m} . \mathrm{snm}$, pasando por superficies de diferentes características: (a) por arenales, hacia el Norte y especialmente hacia el SE del Pukara de Turi, donde el trazado difícilmente se reconoce debido a la acción del viento sobre el plano y algunos hitos o amontonamientos bajos de piedras sirven de señalizadores de su trayecto; (b) sobre rocas donde el tráfico se manifiesta por la erosión y desgaste del suelo de liparitas o ignimbritas, especialmente en el tramo El Encuentro-Pila y en el sector de Cerro Verde, y (c) por lugares areno-pedregosos donde el despeje de piedras va marcando la trayectoria, como es en el sector de Cupo, Pukara de Turi, norte de Pila y de allí a Cerro Verde y el tramo Caspana-Incahuasi. En ninguno de estos casos las piedras sacadas fueron ocupadas para construir un muro lateral, ni para demarcar los límites adyacentes, sino que fueron removidas y tiradas lejos de los bordes. Es justamente este último tipo de camino que Hyslop (1993: 63) señala estar bien ejemplificado por tramos en la red vial incaica que atraviesa el desierto de Atacama.

Por otro lado, existen otros elementos formales de construcción que nos sugieren la obra de ingeniería incaica, como la escalera, los muros de re- tención-contención y el empedrado del camino Cementerio Los Abuelos-capilla del alto." Este camino ha sido ocupado continuamente por la gente de la comunidad, especialmente en momentos de fiestas religiosas donde peregrinan con sus imágenes sagradas, en andas, hacia la capilla del alto. El buen estado de conservación que hoy muestra seguramente se debe a trabajos de mantención y restauración por parte de la comunidad. Existen muchos antecedentes de limpieza de caminos en los Andes y también en los relatos de Francisco Saire, caspaneño, quien nos contara que anualmente se hacía la limpieza del camino Caspana-Río Grande en comunidad y compartido entre ambos pueblos (Castro y Varela 2000). Acerca de las escalinatas en los caminos incaicos, Hyslop (1992) señala que son de distintas variedades y usualmente están hechas de piedras comunes que pueden o no tener algún trabajo, $y$ que junto con los trazados en zig-zag son las dos formas de encarar las pendientes de gran inclinación. Por otro lado, las escalinatas con los peldaños tallados en la roca, como el segmento más bajo de la escalera de Caspana, no fueron reconocidos por Hyslop en los caminos del dominio imperial al sur del lago Titicaca. Acerca de los trazados en zig-zag, agrega que son relativamente comunes desde Ecuador hasta Argentina y existen preferentemente en caminos sin construcciones formales. La combinación de caminos en pendientes cuesta arriba y cuesta abajo con pendientes laterales han sido solucionados en la vialidad incaica con muros de contención con trazos en zig-zag, ejemplo que Hyslop cita a través de los estudios de K. Stothert en el área boliviana. La bajada en zig-zag de Tchapolkolo se ajustaría teóricamente a este patrón incaico de solución de caminos en un sector sobre suelo de rocas y con combinación de pendientes laterales con pendiente cuesta arriba-cuesta abajo. Los hitos o amontonamientos de piedras, señalizadores del camino, en los tramos Turi-El Encuentro y Cerro Verde-Caspana son otros elementos descritos por Hyslop (1992) y Niemeyer y Rivera (1983) que se asocian al camino incaico de Atacama, así como otras pequeñas estructuras en " $U$ " y paravientos en forma de coma que hemos registrado especialmente en el tramo Caspana-Incahuasi. Para los dos últimos tipos de estructuras, si bien las dimensiones y formas generales son semejantes a las del salar de Atacama, éstas difieren en que las primeras presentan una 
hilada y las segundas doble hilada.

En relación al material cultural recolectado en la superficie de las estructuras, vemos que sustancialmente se diferencia de las recolecciones hechas por Niemeyer y Rivera (1983) en dos aspectos muy significativos: (a) ausencia de fragmentos cerámicos propiamente incaicos, sólo en una estructura se halló fragmentos rojo alisados de Turi y en otra cerámica decorada negro sobre rojo; (b) mucho menor presencia de material cultural, que en su mayoría corresponde a desechos líticos gruesos, que recuerdan a la industria lítica del Formativo. En este sentido, el estudio de caminos exige extenderse a regiones mucho más amplias que las aquí recorridas, es así que se vuelve interesante incorporar zonas más distantes como la subregión del río San Pedro y el Alto Loa hacia el norte, y la cuenca del salar de Atacama hacia el sur, con el objeto de integrar a través de la red vial segmentos del territorio bajo el dominio imperial y visualizar a través de ella su organización territorial.

En relación a ésto, es que se muestra de gran interés el sitio arqueológico que denominamos Ojos de Cupo. Este yacimiento parece ser un importante lugar de campamento, seguramente utilizado desde tiempos muy remotos a juzgar por la presencia de arte rupestre del Arcaico Tardío y Formativo. Asimismo, otros estilos de arte rupestre presentes en el sitio y el material cerámico de superficie nos señalan la presencia de población local durante los períodos Intermedio Tardío y Tardío. La presencia de loza, vidrio, latas conserveras y petroglifos de camiones, extienden su ocupación a períodos históricos y actuales. Geográficamente esta abra conecta la subregión del río Salado con la del río San Pedro, donde existen otras evidencias del Tawantinsuyu (Castro 1992). El sitio se manifiesta con gran potencial para aportar en el conocimiento de la movilidad poblacional interregional, si consideramos además su localización en relación al paso cordillerano que conecta esta subregión del Alto Loa con la zona altiplánica meridional boliviana, específicamente con las cuencas hidrográficas del Lípez y Quetena. Por otro lado, tenemos las informaciones vertidas por Bertrand (1885) en relación a la "posta" incaica de la rinconada Chac-Inga, pasando el Cerro LayLay. Este mismo cerro es señalado en la red vial de Le Paige (1958-59), por cuyos faldeos pasaría el sendero que se dirige a Cupo, Topayín y Turi, y hacia el oriente a tierras bolivianas. Ahora hacia el sur, los colegas Uribe y Carrasco hicieron un primer reconocimiento pasando por Yerba Buena y Likan, encontrando en este último lugar petroglifos de felinos moteados semejante a los identificados en el río Salado asignados al período Tardío (Gallardo et al. 1999).

Como se ve, no cabe dudas que los caminos sirvieron para unir lugares poblados, de interés económico, de peregrinaje, sagrados, y finalmente como símbolo omnipresente del poder y autoridad del Estado Inca. En relación a esto Núñez (1981) opina que "la construcción del camino incaico en el norte de Chile está relacionada con la conquista misma del territorio", y cuestiona la teoría de la red vial preexistente de Le Paige (195859), señalando que parte de esta red fue construída con posterioridad a la dominación incaica. Esta aseveración lamentablemente no ofrece mayores detalles, pero en lo que concierne al segmento por nosotros prospectado vemos que este camino une sitios de filiación incaica hoy bien documentados e incluso otros más antiguos. En este sentido, Núñez le resta importancia a las rutas del tráfico caravanero preincaico que durante siglos mantuvo comunicados los pueblos de Atacama, con Tarapacá, Bolivia, el Noroeste Argentino y regiones meridionales. Al respecto, pero más específicos son Niemeyer y Rivera (1983) quienes al referirse al camino del Inca en el sector comprendido entre Peine y Juncal señalan:

“... aparece como una responsabilidad inca, puesto que no se han encontrado restos de cultura material de época anterior, correspondiendo todos ellos a elementos de influencia inca, inca propiamente tal, y aún de desarrollos locales de época incaica como es la cerámica descrita, los pocos objetos líticos y la "manopla" de cobre. El camino en este sector se vincula a ramales ubicados siempre hacia el Este y que se dirigen a explotaciones mineras o a santuarios, como al Llullaillaco, Salín, Socompa."

Por otro lado, Hyslop (1992: 94) plantea que el camino incaico que atraviesa el desierto de Atacama es un buen ejemplo de un trazado realizado con fines administrativos: 
"Constituía la ruta más corta entre el Cuzco y la importante región central de Chile. Debió tener poca importancia desde el punto de vista militar. puesto que el agua es sumamente escasa, lo que hubiera hecho muy dificil sino imposible la marcha de ejércitos. Las tropas que se enviaban a la región central de Chile lo hacian por la vertiente oriental de los Andes."

Sin embargo, a este segmento de un "troncal" que estaría documentado desde Peine hasta Copiapó, se le anexaron otra cantidad de ramales de importancia económica, administrativa y religiosa, como nos sugiere el tramo prospectado Cupo-TuriCaspana-Incahuasi, y gran parte de ellos, coincidiendo con caminos preexistentes que unían poblaciones locales del Intermedio Tardío. Además los sitios localizados en el Alto Loa (Castro 1992) y el segmento del camino inca aledaño al curso del río Loa hacia el norte (Berenguer 1994), hacen pensar que quizás la continuación del incañan o capacñan de fuerza administrativa, mencionado por Hyslop (1993) para el tramo Peine-Juncal, siguió aquellos rumbos. $Y$ en este sentido es que se tendría que encontrar o descartar en terreno la unión más lógica entre estos dos tramos, quizás vía Incaguasi del Alto Loa, Atahualpa, Chuquicamata, Quimal, como lo sugiere tentativamente Muñoz (Varela $1999 \mathrm{Ms}$ ). O, simplemente suponer una estrategia complementaria de construcción y uso, en la cual se incorpora la "infraestructura" preexistente, especialmente cuando tiene relación con aspectos económicos como la explotación agrícola y minera, y en otras ocasiones el dominio se remarca en la construcción de caminos nuevos que van dejando huella junto con la incorporación de nuevos territorios.

Concordamos con Hyslop (1993: 99) que el trazado de los caminos incaicos estuvo determinado por una combinación de factores geográficos y culturales

“las influencias culturales más importantes fueron, por lo general, las zonas de alta densidad poblacional y/o donde se desarrollaban actividades de interés específico para los Incas, acá definidas simplemente como religiosas, militares, administrativas y económicas."

Así los centros de población preincaicas fueron factores que influyeron la dirección de la red vial imperial, también sus caminos, cuya construcción debió ser una importante actividad si pensamos en unir zonas ecológicamente distintas, a través de relaciones económicas complementarias, como sucediera en los Andes desde tiempos antiguos. En el futuro, por lo tanto, sería interesante incorporar al segmento prospectado, al menos dos sitios del Período Intermedio Tardío, uno de gran importancia agrícola como Paniri, y Likan de Toconce por su importancia poblacional (Aldunate y Castro 1981).

\section{Agradecimientos}

Comprometen mis más sinceros agradecimientos mis colegas y amigos Victoria Castro, Mauricio Uribe, Leonor Adán, Patricia Ayala, Carlos Carrasco y la etnohistoriadora Viviana Manríquez. Quiero además agradecer muy especialmente a la amiga y baquiana Virginia Panire de Turi, a Jerónima Salvatierra, Francisco Saire de Caspana, al padre Jorge Astrosa de la comunidad mercedaria, a don Luis Zambrano baquiano y chofer de la zona, y a Pilar Alliende por su constante incentivo. 


\section{BIBLIOGRAFIA}

ADAN, L.. y M. URIBE. Cambios en el uso del espacio en los 1997 períodos agroalfareros: Un ejemplo en la ecozona de quebradas altas, localidad de Caspana (Prov. del Loa, II Región). Actas del II Congreso Nacional de Antropología Chilena Tomo II, pp 541555, Santiago.

ALDUNATE, C., y V. CASTRO. Las chulpa de Toconce y 1981 su relación con el poblamiento altiplánico en el Loa Superior. Período Tardío. Tesis de grado de Licenciado en Filosofía con mención en Prehistoria y Arqueología, Universidad de Chile, Santiago.

BERENGUER. J. Recientes hallazgos de evidencias incai1994 cas en el sector Santa Bárbara, Alto Loa. Boletín de la Sociedad Chilena de Arqueología 18: 10-18, Santiago.

BERTRAND, A. Memoria sobre las cordilleras del de1885 sierto de Atacama y rejiones limítrofes, presentada al Señor Ministro del Interior. Imprenta Nacional, Santiago.

CAÑETE y DOMINGUEZ, P. V. Documento $\mathrm{N}^{\circ} 2$ del Partido 1974[1791] de Atacama, con notas y bibliografía de Horacio Larraín. Norte Grande vol. 1, No2: 243-251, Instituto Geográfico, Universidad Católica de Chile, Santiago.

CASTRO, V. Nuevos registros de la presencia inca en 1992 la provincia de El Loa. Gaceta Arqueológica Andina vol. VI, N²1:139-154, Lima.

CASTRO, V., y V. VARELA. Así sabían contar. Oralidad 3: 199] 16-27, Anuario para el rescate de la tradición oral de América Latina y el Caribe, UNESCO, La Habana.

2000 La dimensión ceremonial en los caminos del Inca. Una reflexión desde la etnografía. Actas de XIV Congreso Nacional de Arqueología Chilena pp. 815-839, Copiapó.

GALLARDO, F., C. SINCLAIRE y C. SILVA. Arte rupestre, 1999 emplazamiento y paisaje en la cordillera del desierto de Atacama. Arte rupestre en los Andes de capricornio, pp. 57-96. Museo Chileno de Arte Precolombino y Banco Santiago, Santiago.

GONZALEZ, A.R. Patrones de asentamiento incaico en una 1980 provincia marginal del Imperio. Implicaciones socio-culturales. Relacio- nes de la Sociedad Argentina de Antropología, Tomo XIV. $\mathrm{N}^{\circ} 1: 63-82$, Buenos Aires.

GUAMAN POMA DE AYALA, F. Nueva coronica y buen 1993 [1616] gobierno. Franklin Pease, (Ed.) Fondo de Cultura Económica, 3 vols. Sección de Obras de Historia, Lima.

HYSLOP, J. The Inca road system. Academic Press, 1984 Inc. Orlando, Florida.

1992 Qhapaqñam. El sistema vial incaico. Instituto Andino de Estudios Arqueológicos, Petróleos del Perú, Epígrafe S.A. (Eds.), Lima.

HYSLOP, J., y M. RIVERA. An expedition on the Inca road 1984 in the Atacama desert. Archaeology vol. 37, $\mathbf{N}^{\circ}$ 6: 33-39.

LE PAIGE, G. Antiguas culturas atacameñas en la cor1958-59 dillera chilena. Epoca Neolítica. Anales de la Universidad Católica de Valparaíso 4-5, Valparaíso.

MOSTNY, G. Ciudades atacameñas. Boletín del Mu1949 seo Nacional de Historia Natural Tomo XXIV: 125-211, Santiago.

MUÑOZ, S. Jeografía descriptiva de las provin1894 cias de Atacama y Antofagasta. Imprenta Gutemberg, Santiago.

NIEMEYER, H., y M. RIVERA. El Camino del Inca en el 1983 despoblado de Atacama. Boletín de Prehistoria de Chile 9: 91-193, Santiago.

NUÑEZ, P. $\quad$ El camino del Inca. Creces, vol. 2, N 1981 10: 49-57, Santiago.

PIZARRO, P. Relación del descubrimiento y con1986 [1572] quista de los Reinos del Perú. Pontificia Universidad Católica del Perú, Fondo Editorial, Lima.

RAFFINO, R. Inca Road research and Almagro's route 1995 between Argentina and Chile. Tawantinsuyu 1: 36-45, Brolga Press Pty Ltda, Sidney.

SAN ROMAN, F. Desierto y cordilleras de Atacama. 1896 Imprenta Nacional, Santiago.

SANTORO, C. Camino del Inca en la sierra de Arica. 1983 Chungara 10: 47-55, Arica.

URIBE, M. Religión y poder en los Andes del Loa: 
1996

Una reflexión desde la alfarería. Memoria para optar al Título de Arqueólogo, Facultad de Ciencias Sociales, Departamento de Antropología, Universidad de Chile, Santiago.

VASQUEZ DE ESPINOZA, A. Compendio y descripción de 1948[1629] las Indias Occidentales. Transcrito del manuscrito original por Charles Upson Clark, Smithsonian Miscellaneous Collections, Vol. 108, Washington.
VARELA, V. 1992

1999 Ms
De Turi pueblo de gentiles a Toconce pueblo de alfareros. Tesis para optar al Título de Arqueólogo, Facultad de Ciencias Sociales, Universidad de Chile. Santiago.

El Camino del Inca en las quebradas altas de la provincia de El Loa, Chile. Enviado a Chungara, Arica. 
